\title{
Portfolio generation goes beyond project selection: Interdependencies must drive new alternatives creation
}

\author{
A geração de carteiras ultrapassa a seleção de projetos: Deve ser \\ guiada pelas interdependências entre os projetos
}

\section{Paulo Tromboni de Souza Nascimento'}

\begin{abstract}
The portfolio management literature mainstream, the Project Selection Paradigm, regards projects as closed packages ready for choice. However, to generate a portfolio, such packages must be opened to reveal the inside sources of interdependencies among them. Then, the project elements so found may be recombined into new alternatives that better capture the synergies among projects and avoid negative interactions. Thus project selection can be superseded by a Project Portfolio Generation based on a projects' and portfolios' reformulation process.
\end{abstract}

Keywords: Portfolio management. Multi project management. Portfolio integration. Project interactions.

Resumo: Centrada na Seleção de Projetos, a literatura de gestão de carteiras trata os projetos como pacotes fechados prontos para escolha. Contudo, para gerar uma carteira, tais pacotes precisam ser abertos para revelar as fontes interiores das interdependências entre eles. Na sequência, os elementos dos projetos encontrados nessa análise podem ser recombinados em novas alternativas que melhor expressem as sinergias entre os projetos e evitem suas interações negativas. Assim, a mera Seleção de Projetos pode ser superada por um processo de Geração da Carteira de Projetos que se apoia num processo de reformulação de projetos e carteiras.

Palavras-chave: Gestão de carteiras. Gestão multiprojetos. Integração da carteira. Interações entre projetos.

\section{Introduction}

To a large extent, managing growth and innovation is managing projects and project portfolios (ARCHIBALD, 1988; BOWEN et al., 1994a, b). It is a complex and uncertain activity. This poses challenges and brings about opportunities to project portfolio management (PPM) that are not currently being addressed. In short, PPM literature has been devoting too much attention to project selection and too little attention to new alternatives generation based on interactions found among proposals and projects in the current active list.

The article begins with some decision theory ideas about complex and uncertain decisions and then proceeds to suggest a formal model of the project selection process, here called the Project Selection Paradigm (PSP) - the current view. Project selection leads to project evaluations, then to evaluation of interactions among projects and finally to portfolio's evaluations constrained by resource availability. These portfolio evaluations are then applied to the choice among projects, moderated by vaguely stated strategic concerns.

The article then continues by criticizing the limitations and oversights of this formal model and challenges the excessive reliance on very uncertain quantitative evaluations to define the approved set of projects.

From there, this author arrives at the conclusion that the main value of PPM is lost if this formal process were really followed to the letter. And this is because the comparisons among projects that lead to interaction evaluation require interaction identification and deeper understanding of the risks and opportunities of the current strategy. In their turn, deeper understood project interactions suggest new portfolio alternatives to achieve better results by recombining projects' assumptions, goals, and resources.

\section{Decision theory and alternative generation}

Decision theory began as a theory of choice (SIMON, 1957a, b) among given alternatives. The subtext here was that man has limited information processing capability, which leads him to simplify its view of his environment - his models of the complex situations in which man finds himself. When making

\footnotetext{
Business Department, School of Economics, Business and Accounting, University of São Paulo - USP,

Av. Professor Luciano Gualberto, 908, Butantã, CEP 05508-010, São Paulo, SP, Brazil, e-mail: tromboni@ usp.br
} 
a decision, he would also tend to consider a limited set of alternatives and their consequences, due to his processing limitations and the complexities and uncertainties of his environment.

To be a choice, at least two alternatives must be known in enough detail to allow an informed decision at the selection occasion. Now, either alternatives are already known, a priori, or they must somehow be found and made available in appropriate form at the time of decision. This leads to a search for alternatives.

Cyert and March (1963) suggested the concept of problemistic search which follows simplified rules like: search in the vicinity of current solutions and satisfying instead of maximizing criteria. Thompson (2006) suggested that, due to environmental uncertainty, opportunistic surveillance should be added. Otherwise, companies would not see new opportunities in their changing environment. Here Thompson follows Penrose (1959), who saw a company's leadership ability to find opportunities as its most important asset.

This search for alternatives can sometimes become very expensive and lengthy. This is usually the case due to insufficient knowledge or conflict among involved decision makers (HICKSON et al., 1990; MARCH, 1978; QUINN, 1977), as when there is:

- Not enough knowledge to find or develop alternatives;

- Limited knowledge about the consequences of alternatives;

- Conflict among those differently affected by differing alternatives;

- Disagreement on the consequences of each alternative; and

- Disagreement about the future situation surrounding the decision implementation.

Such ignorance or conflicts often lead to re opening the decision when unexpected situations arise during the decision process or even after implementation begins. Mintzberg et al. (1976) call these events interruptions. All this is very common in strategic (QUINN, 1980), large project, and project portfolio decisions.

Taking another tack, at least one alternative must be known. Often there is no ready made alternative or no easy to change previous solution. Other times the known alternatives consequences are all very unattractive. Such situations make choice, if not impossible, at least very difficult. And this leads to alternative development. More generally, the search for alternatives can become an effort to develop alternatives when problems, opportunities, and applicable technologies become complex and not well known, and the environment becomes more complex and uncertain.

Decision theory then began to pay attention to complex decision situations where alternatives must be developed before the decision is made (CYERT; MARCH, 1963; MINTZBERG et al., 1976; SIMON; 1960; RAIFFA, 2002). Soon it became clear that alternative development is also part of the solution in conflictive situations. That is exactly the role of negotiations among interested parties: to arrive at mutually acceptable alternatives. But, it is also clear that alternative generation requires technical, organizational and market knowledge and the ability to assess how they interact when put together in the same portfolio: either linearly or non linearly, in reinforcing or destructive ways.

Here it is important to realize: what is project formulation if not alternative development? And what is portfolio generation if not alternative generation? In strategic or portfolio decisions, alternative development is of central concern.

Alternative generation (or development) requires lots of preparatory decisions that define the space for alternative generation concerning assumptions, goals, available means, undesirable results, constraints, technology options, supplier options, just to name a few. A ready for decision alternative involves a large collection of preliminary decisions orderly put together. That is what a ready for decision project proposal really is - a collection of decisions, internally structured for implementation, plus a lot of data projections - based on projection methods, and external data, both, it is hoped for, carefully screened for relevance - so that an informed decision can be taken first on the feasibility and then on the attractiveness and risks of the whole package.

So, for PPM, decision theory seems to imply a careful search for alternatives and consideration of their consequences, as well as the development of new alternatives when none is available or the current ones are not good enough.

However, as shown bellow, PPM seems to have been modeled after the early choice theory of decision making.

\section{The project selection paradigm and its limitations}

To create such an ideal construct as the Project Selection Paradigm it becomes necessary to cite authors with a rather sophisticate view of PPM that also express very clearly the paradigm. In no way it is the intention here to reduce to this model all the richness of such author's writings. As will become clear in latter sections, the literature also includes the seeds of the required criticisms, sometimes even stated by the very same authors that better express these essential assumptions. Of course, one purpose of exercises such as this one is to clarify such theoretical conflations. The model's aim is to try to simplify and make explicit underlying assumptions, thus allowing 
an impersonal criticism and the development of other views. But conceptual and theoretical progress requires precision, implying more rigor and formalization. So let us proceed even at the risk of some undue criticism.

Usually, PPM authors stress the resource constraints and the relevance of the choice of the better projects among the proposed ones. Cooper, Edgett and Kleinschmidt (2001, p. 362) give a classical definition of portfolio management as project selection:

Portfolio management is a dynamic process, whereby a business's list of active new product (and R\&D) projects is constantly up-dated and revised. In the process new projects are evaluated, selected and prioritized, existing projects may be accelerated, killed or de-prioritized; and resources are allocated and re-allocated to the active projects.

Projects here are seen as closed packages to be chosen or rejected. And this provides the point of departure for our criticism. The authors further elaborate the above definition stressing the characteristics of the decision process that results in the list of active projects. For them (2001, p. 362):

The portfolio decision process is characterized by uncertain and changing information, dynamic opportunities, multiple goals and strategic considerations, interdependence among projects, and multiple decision-makers and locations.

Given such a complex and uncertain decision process, Cooper, Edgett and Kleinschmidt (1998) stress the role of their stage gate selection process. Project formulation is managed here. Assumptions, objectives and goals, means, partners, and the large number of preliminary decisions required are handled here through phases that successively go through ever deepening details and estimation tasks until a good proposal is arrived at. And after that, during execution, frequent formal assessments, called gates, systematically check all those elements, their adequacy to environmental requirements or internal consistency, as well as execution goals attainment. Strategy drives the selection criteria at decision gates. Portfolio reviews serve as checking points. Their main purpose is to verify if the process is working well and correct mistakes. The critical point here is that, in this process, each project is assessed in isolation, and either passes a gate, sometimes with recommended changes, or is put on hold. Nowhere are the projects jointly considered for reformulation. That is why they recommend periodic portfolio reviews as a means to check the stage gate process results.

But, the authors also recognize an alternative process dominated by extensive and frequent portfolio reviews. For them, this second option is required in industries facing turbulent environments. Again, projects are seen as complete and closed entities. They are either included or excluded from the active list.

Once the best proposals and the current active projects are known, and alternatives and their foreseeable consequences have been appraised, its time to choose. So the selection or choice of the right set of projects becomes the PPM literature's main worry. And how the literature proposes to make this selection or choice?

The first answer is to directly evaluate the projects' financial potential and to choose the project set that maximizes the portfolio value and still do not violate the resources availability constraints, usually interpreted in financial terms. In the next section, some limitations to this direct approach will be reviewed.

Now, how this evaluation and selection procedure can be formalized? Some assumptions need to be explicitly stated in order to formally proceed to project and portfolio evaluation and portfolio selection, as bellow:

- That there are good proposals in all strategic areas, ready for deliberation;

- That each proposal is a readymade solution that must be accepted or rejected as a whole, a package;

- That the projects list is complete, when the choice process begins; and

- And that the choice will be restricted to this list, with no new projects introduced latter.

Why are these assumptions required? The first condition is required because otherwise the chosen set will not address the uncovered areas, thus not fully expressing the strategic intent (VASCONCELLOS; MONTEROSSI; BRUNO, 2007); and also, because bad proposals will clearly not do the job.

The second assumption is a logical requirement for choice. If it is not satisfied, the definition of the project set will not be a selection or choice, but some other unexplained process. The completeness condition follows because the addition of new projects may change the whole evaluation ranking. The last condition is a reinforcement, to state that outside proposals are to be ignored and will be excluded from the final chosen set.

The conditions or assumptions list above is indeed very restrictive. When explicitly stated, few managers or academics would endorse it. They will rightfully argue that nobody respects or follow them in practice. Also, the process can always be re initiated. But, somewhere along the way, the last iteration will have to follow the above conditions. And, in practice, it is usually sooner than later, Given the large time commitment project selection requires from leaders and high level management.

Unfortunately, these assumptions are also required if we are to proceed with a careful quantitative projects 
and portfolios evaluation as a premise to the project selection! If anyone of them is violated, either the procedure must be re initiated or there is no guarantee of good value, let alone its maximization. There is also the major matter of opening up the selection process, which then ceases to be a choice among well defined alternatives!

Assuming the above conditions are a valid formalization, what are the practices that insure taking them as present in a specific decision situation? At the beginning of the selection procedure, the deciding organization must adopt the following conditions:

- Each project or proposal must be seen as a unit that can not be broken into smaller elements;

- Projects are to be evaluated first in isolation and then in their pair wise or multi wise interactions;

- No new projects or proposals are to be accepted for the duration of the procedure;

- And this implies isolating the formulations and the selection stages of the procedure; selection may only begin after formulation is over; and

- This also suggests to exclude those who prepare and advocate for projects from taking part in the choice of the preferred set.

The last condition above is not a strictly necessary addition to the prior ones, but, besides being a natural assumption after severing formulation from selection, it is also strongly recommended on grounds of fairness and impersonal choice. Anyway, it is a fairly common and recommended practice.

Looking at this paradigm through the decision theory point of view the perspective is clear. Choice is being exercised among ready made alternatives! No matter how they have been arrived at, they are the officially recognized alternatives, supposedly the best set of project options among which the best selection can be made under resource constraints.

\subsection{Limitations of financial evaluations}

If the above PSP formalization is accepted, would not financial evaluations provide the best possible portfolio out of projects selection? Two objections arise.

First, and fundamental, as projects are complex packages with possibly unexpected value interactions among them, there is no assurance that the current list contains the very possible projects that together maximize the portfolio value. On this observation rests this article's contribution.

Second, financial evaluations are next to impossible to be reliably made. Moreover at the beginning of the planning cycles, when projects must be chosen based on poor information gleaned off of very dubious long term projections. This will be dealt with in this section.
Cooper, Edgett and Kleinshimdt (2001), on an empirical result, show that, used in isolation, financial methods result in poor portfolio selection. And in a recent review of portfolio management studies, Killen, Hunt and Kleinschimdt (2007) also confirm this weakness of financial methods. Their main criticism is that the financial evaluations are based on very unreliable projections. To this it must be added that they are based on difficult to clarify assumptions about the pertinent market and social environment, and also on early, underdeveloped, assumptions on the project being assessed.

Freeman (1982) and Pavitt (1990) have had already stated the limitations of financial forecasting for project selection. This claim is much stronger concerning radically new product projects than incremental projects or even radical internal process projects. Freeman (1982, p. 167) even put selection techniques together with "tribal war dances", as rituals to "mobilizing, energizing, and organizing". An EIRMA (EUROPEAN..., 1995) study later confirmed these claims for European firms, at least when financial selection methods are used in isolation.

Hayes, Wheeelright and Clark (1988) criticized what they called the "Modern Capital Budgeting Paradigm", based on discounted cash flows. For them, it is a poor basis on which to base project selection for the unreliability of the projected numbers used and the extreme difficulty of even estimating the potential benefits of capability building embedded in good project proposals. More so, whenever one is dealing with long term propositions.

In parallel, the real options literature (MITCHELL; HAMILTON, 1988) applied to R\&D the criticism that the discounted cash flows rarely, if ever, did take into account the hidden benefits of good projects, like the learning they sometimes provide of entirely new technologies and/or markets, as well as the capabilities acquired even by their unsuccessful conclusion. As Maidique and Zirger (1985) stress, even failed product launches sometimes are a requirement for subsequent successful ones, leading them to postulate a failure and success cycle for new product introduction, which they named the New Product Learning Cycle. And the real function of many projects is, of course, to probe (the market) and to learn (how to do better) (LYNN; MORONE; PAULSON, 1996). Value issues only to become clear very much afterwards.

Later on the financial theorists tried to include the real options in their quantitative models. But, because they based their ideas on the financial markets options, that are clearly defined, they missed the main point. If it is difficult to accurately estimate the costs and revenues of well defined project alternatives, how can one make reliable projections of dimly perceived future options? That is what Adner and Levinthal (2004) made crystal clear addressing the question of 
what is not a real option. That is, project options have not a well behaved temporal and results structure as do financial markets options.

Taking a summation, what seems to be theoretically wrong with financial evaluation methods is:

- Uncertainty can not always be identified, let alone subject to risk estimation; there is such a thing as uncertain uncertainty $(\mathrm{LOCH}$; SOLT; BAILEY, 2008);

- There may be unknown factors affecting possible results and risks (as there always are, particularly at the beginning of a project);

- The figures on such evaluations are always precarious projections;

- Available figures are less reliable early on in proposals formulation;

- Breakthrough proposals have figures even less reliable;

- The proposals preparation costs and time may be significant and require arbitrary allocation of resources prior to selection decisions;

- The expected cost of execution errors is often unknown;

- Project selection, by necessity, includes always well advanced projects and early proposals, and lead to comparisons among figures of widely spread reliability;

- The potential benefits of a project include options, known and newly created, yet impossible or difficult to evaluate;

- The capabilities created by the projects may have a difficult to assess value;

- There may be a significant potential for learning that require time and resources, but whose value is always hard to pin down in figures;

- There may be unclear (and therefore difficult to assess) opportunities for dynamic economies of scope or learning; and

- There may be non financial objectives, which bar easy translation into cost and revenue figures.

One or a few of those difficulties in isolation could perhaps be circumvented by an appropriate assessment method. All together they are enough to justify the poor business record of purely financial project selection methods verified by Cooper, Edgett and Kleinschmidt (2001).

Thus realizing that directly considering financial evaluations are not enough for good portfolio decisions, Cooper, Edgett and Kleinschimdt (1997, p. 27) suggest instead a second answer on how to make the evaluation and selection. They added as further portfolio management objectives that strategic areas of interest must be addressed, as well as portfolio balance. The strategic areas are seen as buckets of money to be spent in them. No criteria are given on how to divide the money among these strategic buckets. Concerning the resulting portfolio balance they explicitly state that there are no a priori criteria to define what should be seen as a balanced portfolio. As stated, these recommendations amount to a loose advice to the application of good judgment.

So the direct financial choice of projects does not work well. On the other hand, there is no clear indication on how to incorporate strategic and balance considerations, even if there is acknowledgement that they should be.

However, the final blow against a directly financial assessment selection process is the need to assess the value of the interactions among projects.

\section{Projects interactions and alternatives generation}

\subsection{Project interactions assessment}

Financial evaluations remain straight forward as long as they work on sets of independent projects. This means that the value of one project does not depend on other projects results and activities. And this includes the technical interrelations among projects, since they become inextricably connected for evaluation purposes if one project depends on the technical results of another. For instance, if the dependent one is included in a portfolio and the other is not, them it has costs but no benefits. Otherwise, their dependence may be reciprocal, as when capability development costs may be spread over many projects instead of being incurred by just one. Or yet, when one project incurs the capability cost that others can later to freely tap on.

The real point, of course, is that the value of a portfolio is a simple linear sum of the included projects values if and only if they are independent. Otherwise, all kinds of restrictions and functional relationships may apply to the evaluation of a specific portfolio. Moreover, the evaluation of different portfolios may need differing constraints and functional relationships. Gone is the mathematical simplicity of the financial evaluation. And also its generality! No longer, a simple summation function connects individual projects and portfolio evaluations. Moreover, individual projects values vary whenever they interact among themselves in the projected future jointly created.

Now, the task of the portfolio creator is no longer a simple selection.

First, one has to jointly evaluate projects in each different portfolio, as it is not a priori given what kinds of relationships will prevail among the included projects. And this, of course, makes it imperative to find out what relationships stand out among projects, 
including of course the possibility of interdependency among some special project sets (here, in particular, seems to rest the value of the platform concept advocated by Wheelwright and Clark (1992)).

Verma and Sinha (2002), looking for a theory of interdependencies in $\mathrm{R} \& \mathrm{D}$ portfolios in a dynamic context, mention 3 kinds of interdependencies that impact projects' results and performance measures: resource interdependency, technology interdependencies and market interdependencies. Resources interdependencies applies to projects requiring the same capabilities for their development, therefore requiring priority decisions for the allocation of people, money and physical assets. Technology interdependencies refer to the state of development of some technology, to the internal knowledge and control of required technologies, to its level of modularity, and to the level of technology commonality among projects. Market interdependencies are conceptualized as the ability to use knowledge about well exploited markets to develop new products and explore new markets.

Certainly, this categorization and conceptualization can be further ameliorated. For instance, market interdependencies do not end at the knowledge level. It is also concerned with potential leveraging of brands, and business relationships, and from established infra structures, as well as market cannibalization relationships among projects. But it is enough for this article's purposes.

Faced with the need to evaluate project interactions in the context of each portfolio, the financial evaluators proceed to establish the value of such interactions and take them into consideration in their financial analysis. Well, herein lays a caveat. Precarious financial figures become even more precarious when complex and dimly perceived relationships that depend on projects technical results and future market outcomes must be taken into account.

Worse still, where is it established that the existing relationships, good and bad, found by comparisons among projects and portfolio analysis must be endorsed?

Now, interrelationships can appear among projects in two ways: deliberately, as part of the strategy implementation, or unintentionally, accidentally or caused by unintended results at the project formulation level. Either the interactions results from top down strategic guidance which appear in the assumptions and elaboration of each interrelated project, leveraging some capability for instance, or from different teams preparing different bottom up proposals finding similar or conflicting market or technological conditions that afterwards appear as commonalities or conflicts in the portfolio reviews.

If arising from strategic guidance, commonalities among projects reflect the intended strategy, probably in the form of desired competitive advantages or distinctive capabilities development, implementation, or leveraging. On the other hand, conflicts among projects and proposals may suggest inconsistency in the strategic guidance as a whole or its inadequacy to environmental requirements or still organizational lack of alignment with the current strategy. They represent surprises to be understood and adequately considered in final portfolio decisions.

If unintended, conflicts or commonalities among projects and proposals require understanding of what risks or opportunities lay hidden behind them.

Now, here lies the central argument of this article. What is the point of proceeding to the choice among projects before detailed assessment of such revealed connections among projects, without understanding deeply their origins and potential and without accordingly amending the projects in the approval list, before making any final decisions and commitments?

\subsection{Interactions and new alternatives}

To answer the above question, projects must be seen as complex packages to be unpacked. They must be reopened and jointly examined in their elements, objectives, intended results, assumptions, detailed activities, and required market and technological capabilities. Then, negative interactions may be avoided by suitably changing the projects. And positive interactions may be reinforced in order to get the most out of each set of interacting projects, possibly implying considerable revision of pertinent projects. The result of such changes is certainly a set of portfolios more tightly integrated around positive interactions among sets of projects and proposals, either strategically intended or serendipitously found.

Up to a certain point at least, more integrated portfolios will probably have more value to the company, at the expense perhaps of more risk, if not suitably hedged by some exploration investments (LYNN; MORONE; PAULSON, 1996). Danny Miller (1993) has suggested that too much simplification and integration around an explicit strategy may lead a company not only to greater efficiency and effectiveness under the current environmental conditions but also to its corporate death, because it would take out their capabilities and resources required to confront surprising environmental changes. On the other hand, to avoid excessive simplification can only be done if the project selection paradigm is denied control of the portfolio generation process, specially an early control.

In order to get to the best list of approved projects, taking into account their interactions, managers must open up the list of original alternatives to include new ones. These, in their turn, will come out of searching for the elements in each project or proposal that 
could cause the negative or positive interactions, and from their suitable reformulation to arrive at new projects and portfolios designed to reduce unintended conflicts and promote desired synergies. And this denies assumptions b), c) and d) in the above formal expression of the project selection paradigm.

In addition, it is often the case that the current list of projects does not follow some intended strategy guidance. As Vasconcellos, Monterossi and Bruno (2007) shows us, it may be the case of stimulating the elaboration of proposals including these strategic suggestions or at least modifying some projects or proposals in order to accommodate the forgotten guidance. Otherwise, it may also become clear that a change of strategy is required. In any case, this lack of sound proposals must be analyzed as strategic feedback from the portfolio review process.

And, as Balachandra and Raelin (1983), Wheelwright and Clark (1992) or Cooper, Edgett and Kleinscmidt (1998) tell us, all this reshuffling of projects and project elements will not be over without killing or substantially reducing the scope of some projects. Sharpe and Keelin (1988) expressly recommend an alternative generation phase, to experiment with expanded and reduced scopes for each project.

So, all this allows a very basic conclusion. A company may embark upon a portfolio selection through the financial evaluation of project interactions in the possible portfolio combinations. But it may get a more valuable portfolio if it tries to generate its portfolio opening up its projects and proposals in search of the causes of negative and positive interactions among projects.

Furthermore, this requires a deeper and more complex review and analysis, targeted at uncovering the interdependencies among them and their value repercussions. And this leads to new alternatives generation (development) as a consequence of portfolio analysis and evaluation, which here mostly function in qualitative terms to reveal the hidden interdependencies among projects and proposals and their value repercussions.

\subsection{New alternatives based on projects' interactions}

Unsurprisingly, academics and managers know a lot about these interdependencies that plague portfolio generation. Duplications, market conflicts, brand conflicts, parts proliferation, resources specifications and utilization conflicts, unexpected market segments discoveries, unexpected technology applications, unexpected finding of possible partners, lack of technology, unexpected costumer preferences, competition from unexpected quarters, capability development and implementation, are some among an almost infinite array of possibilities.

Also companies have departments, groups and methodologies looking for these interactions: $R \& D$ groups, strategic planning groups, market intelligence groups, technology assessment groups, as well as methodologies such as aggregate project planning and portfolio reviews, which oversee several projects, steering committees, etc. There is a lot of institutional attention devoted to interactions among projects and between them and current or future operations. The problem is that the Project Selection Paradigm does not have a place to channel the knowledge thus made available into better project alternatives. To this mode of operation projects are closed packages once they enter the selection process.

And the literature does anticipate the above conclusion.

Sharpe and Keelin (1998) clearly recommend a process of alternative generation before portfolio selection, because they see it as a too restrictive, an all or nothing, selection process that considers only the current plan for each project as a viable alternative. Accordingly, they constrain this new alternative generation to each project in isolation, contemplating the current project plan, scope enlargement and reduction, as well as a minimal plan (killing the project preserving as much as possible earned value to date).

Clark and Wheelwright (1993, p. 259) also state that project selection is "More than just 'picking projects' from the existing list [...]", and further indicate that this implies "[...] to repackage and reformulate projects in order to define the set that offers the greatest opportunity given the firm's strategy and resources $[\ldots] "$.

For Wheelwright and Clark (1992), product and process project formulation and selection follows strategy. Strategy in its turn requires product and process projects to be clearly articulated as breakthroughs, platforms and derivatives. Breakthrough projects are the source of upcoming platforms and implement radically new ideas. Platforms are the main source of medium term revenue and the basis of current and near future competitive advantage. And derivatives are the way to fully exploit a platform's market, revenue, and profits potential. For them the level of process change must be linked to the level of product innovation. Otherwise business objectives would be negatively affected. Uncertainty in projects business results grow from minor in derivative projects to very large in breakthrough ones. Technology and advanced development are seen as separate capability building initiatives, later to be incorporated into product and process development.

They advocate an integrated approach to strategy formulation (Chap. 3), as well as an integrated approach to their "Aggregate Projects Plan" (Chap. 4), 
which is more than a simple "list of active projects". It organizes the projects and their sequencing explicitly based on the relations among the competitive impacts of platform and derivative projects and the time availability of technologies in advanced development. It also explicitly addresses risk issues, segregating radical new products and suggesting an explicit allocation of resources according to risk. They are also explicitly concerned with the impact of projects on capability building and resource use and leveraging.

Projects [...] also have the potential to build new development capability [...] Thus the aggregate project plan needs to identify where the firm intends to make significant changes and how the changes will be connected to product and process projects [...] (CLARK; WHEELWRIGHT, 1993, p. 260).

So, they go further than Sharpe and Keelin (1998) in suggesting that projects must take into account a global perspective on an integrated portfolio conception and even take into account the options value of projects when they stress the capability creation that should be taken into consideration during projects formulation and approval.

Vasconcellos, Monterossi and Bruno (2007), clearly remember us that the active list of projects and proposals may not implement the whole lot of strategic orientations expressed in the business strategy. And this implies that new or suitably modified projects and/or proposals are required in order to fulfill the firm's strategic intent.

If we position our discussion here, and take seriously the suggestions of Clark and Wheelwright, Sharpe and Keelin and Vasconcellos, Monterossi and Bruno, it is clear that the current list of active projects and proposals is just the point of departure of the portfolio generation process.

And it is also clear that the current projects may need to be widely reformulated in order to better serve the competitive and growth needs of the business. Project scopes may change, their objectives may change, their strategies may change, their grouping into platforms and/or product lines may change, their time to market may change, their use of technologies may change to benefit from transfer from other projects (NOBEOKA; CUSUMANO, 1995, 1997), and also to better leverage distinctive capabilities, and so on.

As the above discussion makes abundantly clear, one of the main motives for project changes are their interdependencies. So here, the argument comes back to Verma and Sinha's (2002) market, technology and resource interdependencies.

Let us linger a bit longer on interdependencies. What can they be? The following list may help to identify the kinds of interdependencies among projects that may imply reformulation of projects and portfolios:

- Production, logistic and market scope economies;

- Scale and growth economies arising from common parts and resources indivisibility;

- Learning economies, from cross project technology transfers and capability building and leveraging;

- Unnecessary duplications of capability development;

- Reciprocal product market cannibalization;

- Reciprocal reinforcement in product markets;

- Excessive and unfeasible utilization of critical resources;

- Excessive R\&D resources dispersal without advantageous interdependencies;

- Interdependencies in support markets; and

- New functionalities created by technology development with applications bridging several projects (WARSH, 2007).

This, of course, is not a complete list. But, it is suggestive of typical interactions among projects that must be searched for in a portfolio review. As activities in portfolio reviews, some possibilities may be:

- To identify unexpected interactions among projects and between them and current and future operations;

- To evaluate direction, level of synergy and cumulativity of their impacts on business, current and future;

- To identify the sources of the business impacts of these interactions, meaning shared components and technologies, market synergies, etc.;

- To kill some projects, preserving the earned value in other projects (or in reduced scope ones) if possible and appropriate;

- To modify current projects and proposals to capture possible benefits or avoid risks from the unexpected interactions, assuming, of course, the expected ones are already taken into account; and

- To group projects into highly interacting sets, e.g., platform and their derivative projects.

Once interdependencies are identified and characterized, the task remaining is relating them to current strategy. If compliant with current strategy, it is just the case of comparative assessment. Otherwise, a new task follows. To assess if these newly identified interdependencies among projects either merit inclusion in current strategy, as emergent portfolio or project strategy (ARTTO; DIETRICH, 2007), or should be discarded, leading to portfolio simplification. In the first case, of course, decision makers have to define an exploratory or exploitative 
role (DANNEELS, 2002) for the projects affecting such interdependencies.

\section{Conclusion and research implications}

The main conclusion of this essay is that project selection is not enough for effective and competitive portfolio management. Portfolio generation requires more. It requires the ability to use strategic guidance and portfolio reviews to identify and characterize interdependencies among projects and proposals and to apply them to project and portfolio formulation and reformulation.

The rigid application of the model here named the Project Selection Paradigm may achieve an operational solution to the portfolio management challenge of focusing organizational resources and attention. But it does not address all the business and competitive contribution that explicit consideration of interdependencies in projects' reformulation may bring.

Moreover, in spite of financial evaluation models that address the interdependencies among projects, the main contribution of contemplating interdependencies does not lie in a better financial evaluation of the alternative portfolios. On the contrary, it lies in the redefinition of projects and portfolios to avoid crippling conflicts and to exploit favorable synergies among them. And this requires a view of projects as complex packages that can be opened and rearranged to generate alternatives that better exploit synergies and avoid negative interactions.

To achieve this, interaction and interdependency among projects concerning technology development and sharing, capability building, critical resources conflicts, and competitive advantage in different markets must be key considerations in portfolio's reviews and generation.

\subsection{Research implications}

This is an essay. Even if the assumptions invoked here are well grounded in empirical research, the main conclusion is not. So, validation is required. First, to check if it provides better descriptive models of portfolio generation and management. Second, to verify if it gives better prescriptions.

The view here suggested also requires a major shift in research emphasis. If the validity of portfolio generation transcending portfolio selection is accepted, then portfolio reviews and management must concentrate on interdependencies among projects. The main task is not to develop better quantitative evaluations, but to change the portfolio review process to concentrate inter-project assessment on interdependencies identification and characterization; to create a new phase for new project alternatives generation; to opening up the projects initial list; and to opening up existing projects to a redefinition concerned with inter-projects synergy exploitation and conflict avoidance.

The so called fuzzy front end becomes more important as the concept generation phase that leads to new alternatives. However, research should be done to clarify how this phase will receive feedback from the comparisons leading to projects' reformulation.

The problem of changing portfolio priorities is usually solved changing resource allocation among the projects in the pipeline. However, another possibility is to change objectives and expected results - new alternatives - that emerge in portfolio reviews.

Questions also remain concerning how to make qualitative project assessments that help unravel synergies as well as negative interactions among projects.

One final point may be of relevance. Perhaps, for reasons not discussed here, and so far unknown to the author, the idea of interdependencies driving projects reformulation may be right but would not significantly enhance the portfolio value. Considerations of simplicity may then suggest keeping the PSP as a practical guidance. This author does not believe in this possibility. But this does not mean it must not be checked, at least in particular situations.

\section{References}

ADNER, R.; LEVINTHAL, D. A. What is not a real option: considering boundaries for the application of real option to business strategy. Academy of Management. Academy of Management Review, v. 29, n. 1, p. 74, 2004.

ARCHIBALD, R. D. Projects: Vehicles for Strategic Growth. Project Management Journal, v. 19, n. 4, p. 31-34, 1988.

ARTTO, K. A.; DIETRICH, P. H. Strategic Business Management Through Multiple Projects. In: MORRIS, P. W. G.; PINTO, J. K. (Eds.). The Wiley Guide to Project, Program \& Portfolio Management. Hoboken: John Wiley \&Sons, Inc., 2007.

BALACHANDRA, R.; RAELIN, J. A. When to Kill That R\&D Project. Research Management, p. 30-33, 1983.

BOWEN, K. et al. Development Projects: The Engine of Renewal. Harvard Business Review, p. 110-120, 1994a. BOWEN, K. et al. Make Projects the School for Leaders.

Harvard Business Review, p. 131-140, 1994b.

CLARK, K. B.; WHEELWRIGHT, S. C. Managing New Product and Process Development: Text and Cases. New York: The Free Press, 1993.

COOPER, R. G.; EDGETT, S. J.; KLEINSHIMDT, E. J. Portfolio Management in New Product Development: Lessons from the Leaders - I. Research-Technology Management, p. 16-28, 1997a. 
COOPER, R. G.; EDGETT, S.; KLEINSCHMIDT, E. J. Portfolio Management for New Products. AddisonWesley, Reading, Mass, 1998.

COOPER, R. G.; EDGETT, S.; KLEINSCHMIDT, E. J. Portfolio Management for new Product Development: results of an industry practices study. R\&D Management, v. 31, n. 4, 2001. http://dx.doi. org/10.1111/1467-9310.00225

CYERT, R. M.; MARCH, J. G. A Behavioral Theory of the Firm. Englewood Cliffs: Prentice Hall, Inc., 1963.

DANNEELS, E. The dynamics of product innovation and firm competencies. 2002. Strategic Management Journal, v. 23, p. 1095-1121. http://dx.doi.org/10.1002/smj.275

EUROPEAN INDUSTRIAL RESEARCH MANAGEMENT ASSOCIATION - EIRMA. Evaluation of R \& D Projects. Paris, 1995.

FREEMAN, C. 1982. The Economics of Industrial Innovation. 2nd ed. London: Frances Pinter Publishers, 1995.

HAYES, R. H.; WHEELWRIGHT, S. C.; CLARK, K. B. Dynamic Manufacturing. New York: The Free Press, 1988.

HICKSON, D. J. et al. Top Decisions: Strategic Decision Making in Organizations. San Francisco: Jossey-Bass Publishers, 1990.

KILLEN, C. P.; HUNT, R. A.; KLEINSCHIMDT, E. J. Managing the New Product Development Project Portfolio: A Review of the Literature and Empirical Evidence. In: PORTLAND INTERNATIONAL CENTER FOR MANAGEMENT OF ENGINEERING AND TECHNOLOGY, 2007, Portland. Proceedings... Portland, 2007. http://dx.doi.org/10.1109/ PICMET.2007.4349514

LOCH, C. H.; SOLT, M. E.; BAILEY, E. M. Diagnosing Unforseeable uncertainty in a new venture. Journal of Product Innovation Management, v. 25, p. 28-46, 2008. http://dx.doi.org/10.1111/j.1540-5885.2007.00281.x

LYNN, G. S.; MORONE, J. G.; PAULSON, A. S. Marketing and discontinuous innovation: the probe and learn process. California Management Review, v. 38, n. 3, p. 8-37, 1996. http://dx.doi.org/10.2307/41165841

MAIDIQUE, M. A.; ZIRGER, B. J. The new product learning cycle. Research Policy, v. 14, p. 299-313, 1985. http:// dx.doi.org/10.1016/0048-7333(85)90001-0

MARCH, J. G. Bounded Rationality, Ambiguity, and the Engineering of Choice. The Bell Journal of Economics, v. 9, p. 587-608, 1978. http://dx.doi.org/10.2307/3003600

MILLER, D. The architecture of simplicity. The Academy of Management Review, v. 18, n. 1, p. 116-138, Jan. 1993.

MINTZBERG, H.; RAISINGHANI, D.; THÉORÊT, A. The Structure of "Un Structured" Decision Processes. Administrative Science Quarterly, v. 21, p. 246-275, 1976. http://dx.doi.org/10.2307/2392045

MITCHELL, G. R.; HAMILTON, W. F. Managing R\&D as a Strategic Option. R\&T Management, v. 31, n. 3, 1988. NOBEOKA, K.; CUSUMANO, M. A. Multiproject Strategy, Design Transfer and Project Performance: A Survey of Automobile Development Projects in the
US and Japan. IEEE Transactions on Engineering Management, v. 42, n. 4, p. 397-409, 1995. http:// dx.doi.org/10.1109/17.482089

NOBEOKA, K.; CUSUMANO, M. A. Multiproject Strategy and Sales Growth: The Benefits of Rapid Design Transfer in New Product Development. Strategic Management Journal, v. 18, n. 3, p. 169-186, 1997. http://dx.doi. org/10.1002/(SICI)1097-0266(199703)18:3\%3C169::AIDSMJ863\%3E3.0.CO;2-K

PAVITT, K. What We Know about the Strategic Management of Technology. California Management Review, v. 32, n. 3, 1990.

PENROSE, E. T. The Theory of the Growth of the Firm. Oxford: Basil Blackwell, 1959.

RAIFFA, H. Decision analysis: A personal account of how it got started and evolved. Operations Research, v. 50, n. 1, p. 179-185, 2002. http://dx.doi.org/10.1287/ opre.50.1.179.17797

QUINN, J. B. Strategic Goals: Process and Politics. Sloan Management Review, v. 19, n. 1, p. 21-37, 1977.

QUINN, J. B. Strategies for Change - Logical Incrementalism. Homewood: Richard D. Irwin, Inc., 1980.

SHARPE, P.; KEELIN, T. How Smith-Kline Beecham Makes Better Resource-Allocation Decisions. Harvard Business Review, 1998. [Original de 1985].

SIMON, H. A. A Behavioral Model of Rational Choice. In: SIMON, H. A. Models of Man - Social and Rational. New York: John Wiley \& Sons, Inc., 1957a.

SIMON, H. A. Rational Choice and Structure of the Environment. In: SIMON, H. A. Models of Man - Social and Rational. New York: John Wiley \& Sons, Inc., 1957b.

SIMON, H. A. The New Science of Management Decision. School of Commerce, Accounts, and Finance. New York: New York University; Harper \& Brothers Publishers, 1960.

THOMPSON, J. D. Organizations in action - social science bases of administrative theory. New Brunswick: Transaction Publishers, 2006. [Original de 1967].

VASCONCELLOS, E. P. G.; MONTEROSSI, J. O.; BRUNO, M. A. C. Identification of Technological Threats and Opportunities: Conceptual Framework and Application an Autoparts Company. In: INTERNATIONAL CONFERENCE ON MANAGEMENT OF TECHNOLOGY, 16., 2007, Florida. Proceedings... Management of Technology for the Service Economy, 2007. v. 1, p. 1-126.

VERMA, D.; SINHA, K. K. Toward a theory of project interdependencies in high tech $\mathrm{R} \& \mathrm{D}$ environments. Journal of Operations Management, v. 20, p. 451-468, 2002. http://dx.doi.org/10.1016/ S0272-6963(02)00024-4

WARSH, D. Knowledge and The Wealth of Nations - A Story of Economic Discovery. New York; London: W. W. Norton \& Company. 2007.

WHEELWRIGHT, S. C.; CLARK, K. B. Creating Project Plans to Focus Product Development. Harvard Business Review, 1992. 